\title{
Treatment of Posttubercular Syringomyelia Not Responsive to Antitubercular Therapy: Case Report and Review of Literature
}

\author{
Giuseppe Canova ${ }^{1}$ Alessandro Boaro ${ }^{1}$ Enrico Giordan ${ }^{1} \quad$ Pierluigi Longatti $^{1}$ \\ ${ }^{1}$ Department of Neurosurgery, University of Padova, Treviso Regional \\ Address for correspondence Enrico Giordan, MD, Department of \\ Hospital, Treviso, Italy \\ Neurosurgery, University of Padova, Treviso Regional Hospital, Pzza. le \\ Ospedale 1, 31100, Treviso, Italy (e-mail: egiordan@aulss2.veneto.it).
}

J Neurol Surg Rep 2017;78:e59-e67.

\begin{abstract}
Posttubercular adhesive arachnoiditis is a rare, late complication of tubercular meningitis. Syringomyelia can develop as a consequence of intramedullary cystic lesions and cerebrospinal fluid (CSF) flow disturbance around the spinal cord, even after successful chemotherapy. We reviewed the literature related to posttubercular syringomyelia treatment and suggest a new combined surgical approach. A 25-yearold Nigerian male patient presented with legs numbness, urinary disturbance, and legs weakness. Spinal magnetic resonance revealed a T5-T7 syringomyelia, secondary to adhesive spinal arachnoiditis related to a history of tuberculous meningitis. Adhesiolysis by direct visualization with a flexible endoscope was performed and a handmade sitalic syringe-subdural shunt was placed to restore CSF flow. During the postoperative course, the neurological deficits improved together with the resolution of the syrinx.

Keywords

- posttubercular complication

- syringomyelia

- arachnoiditis

- spinal shunt

- flexible endoscopy Long-term magnetic resonance imaging follow-up documented no recurrences or shunt displacements. We suggest that, when antitubercular therapy is not effective to resolve postarachnoiditis syrinx, arachnolysis with a flexible endoscope together with the placement of an s-italic shunt allowed free CSF communication between the syrinx and the subarachnoid space. Furthermore, we support that the use of an s-shaped shunt could prevent displacement or migration of the device and allows an easier revision in case of acute or late complications.
\end{abstract}

\section{Introduction}

Syringomyelia is a rare pathological condition characterized by the presence of cystic cavities within the spinal cord. The etiopathogenesis is still unclear but it can rarely develop as a complication of tuberculous meningitis (TBM), even after successful chemotherapy. Postinfectious arachnoiditis alters cerebrospinal fluid (CSF) flow into the spinal cord with the possible formation of enlarging cavitation that could lead to a severe myeloradicular compression. ${ }^{1}$ Post-TBM syrinx incidence rate is related to the prevalence of TBM in the community, and has been rarely described in literature with only 30 cases reported so far. ${ }^{2-8} \mathrm{~A}$ precise diagnosis is mandatory to help the physician to adopt the appropriate management and conservative treatment is not effective for post-TBM syringomyelia. ${ }^{9}$ Early surgery is highly recommended before the establishment of gross neurological deficits or in case that spine magnetic resonance imaging (MRI) highlights increased size and extension of the cavity. Surgery can immediately arrest the progression of syrinx with the rapid improvement of symptoms. Shunting procedures are advocated when reestablishment of the CSF circulation is impossible. ${ }^{1}$ However, the choice of treatment should be case tailored. In 2000 Kaynar et al described a case of posttubercular syringomyelia treated with a received

October 7, 2016

accepted after revision

January 18, 2017
DOI http://dx.doi.org/ 10.1055/s-0037-1601327. ISSN 2193-6358. (c) 2017 Georg Thieme Verlag KG Stuttgart · New York
License terms

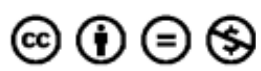


syringosubarachnoid shunt with a silastic "T" tube insertion. The syrinx relapsed after 2.5 years, due to arachnoid thickening and formation of new adhesions and the patient underwent a reintervention with placement of a syringoperitoneal shunt. ${ }^{4}$ Iwatsuki et al in 2014 described a new modified surgical approach in order to minimize the postoperative recurrence of syrinx, when treating syringomyelia associated with spinal adhesive arachnoiditis: partial arachnoid dissection and syrinx-far distal subarachnoid shunt placement. ${ }^{10}$ In this report, we describe a case of a symptomatic posttubercular dorsolumbar syringomyelia. After an extensive review of post-TBM syringomyelia cases, we decided to treat the patients with a double approach: endoscopic arachnolysis and an s-shaped syringosubarachnoid shunt placement.

\section{Case Presentation}

A 25-year-old African male patient was admitted to our infectious diseases department complaining headache, fever, confusion, and a mild weakness of the left hand. After serological tests and brain and spine MRI, a diagnosis of tubercular meningoencephalitis, with right frontal tuberculoma, was made. Antitubercular therapy was administered and the patient progressively recovered and was discharged.
After 2 months, he came back complaining paraparesis with hypoesthesia below $\mathrm{T} 5$ level and bladder dysfunction. Spine MRI scans showed dural enhancement all along the spinal cord and highlighted a lesion, of $6.5 \mathrm{~mm}$ of diameter, at T5-T6 level. In T5-T8 levels the spinal cord appeared edematous with an enlarged centromedullary canal. The patient underwent a T5-T7 laminectomy to obtain the specimen and release the pressure on the spinal cord. The syrinx was not considered for an elective surgical treatment. Steroids and monoclonal antibodies were administered for 3 months with symptoms improvement. At the time of discharge, the patient complaints of mild paraparesis with complete recovery of bladder function.

After 4 months, he was readmitted for worsening of paraparesis. Spine MRI scans documented enlargement of the syringomyelic cavity in the thoracolumbar tract.

The patient underwent spine computed tomography scans with the evidence of an almost complete interruption of CSF flow below the level of D7, site of the previous laminectomy.

CSF analysis was negative for mycobacterium and cells count documented high proteins levels $(107 \mathrm{mg} / \mathrm{dL})$. At this point, it was decided to proceed with the surgical treatment of the syrinx. A double approach was performed: the creation of a syrinx-subarachnoid shunt and the endoscopic navigation of the adjacent subarachnoidal spaces.

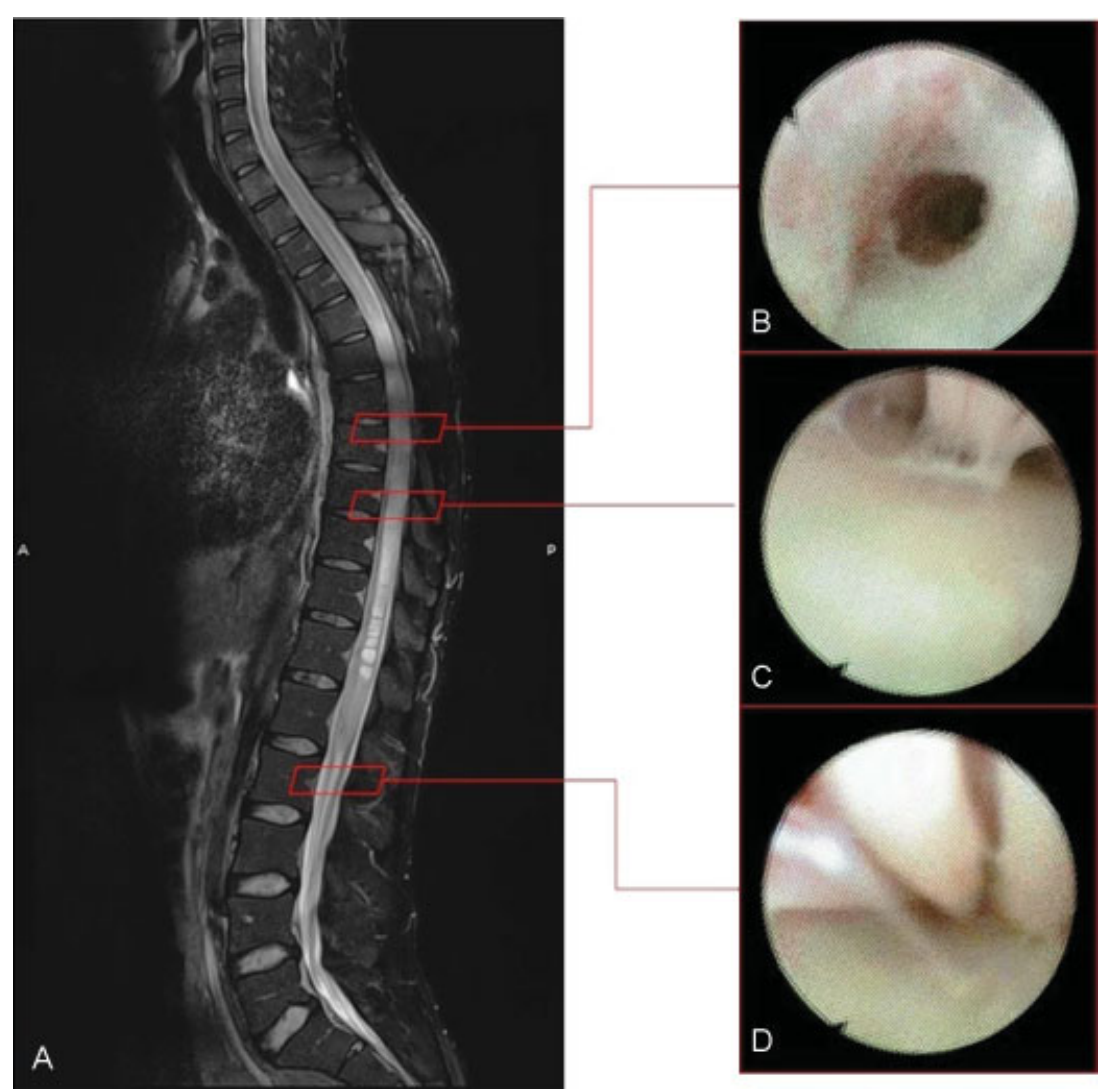

Fig. 1 (A) Midline sagittal T2-weighted preoperative spine MRI showing syringomyelia. (B) Endoscopic imaging: the endoscope through the perimedullar fibrous septae consequent the arachnoiditis. (C) Endoscopic evidence of the fibrous adherences stretched between the cord and the arachnoid layer. (D) Endoscopic view of the roots of the cauda equina and the fibrous septae between them. MRI, magnetic resonance imaging. 


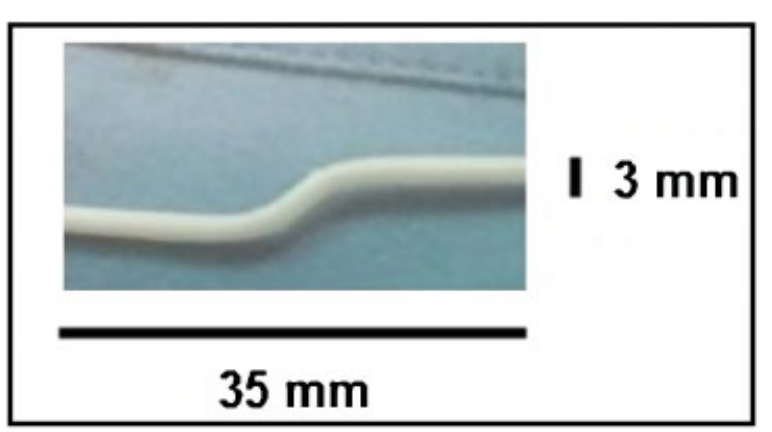

Fig. 2 Picture of the silicon shunt and its measures.

Neurophysiological monitoring was set up to evaluate motor and sensory changes in evoked potentials of lower limbs' muscles (abductor halluces brevis, anterior tibialis, vastus lateralis) and of the anal sphincter. A single level laminectomy was performed. The dura mater and the thickened arachnoid were opened on midline to expose a swollen but still pulsating spinal cord. Myelotomy was performed with forceps and scissors. Clear and transparent pressured CSF flew out. The spinal cord immediately appeared more relaxed allowing the exploration of the posterior subdural space. At that point, a $2.5 \mathrm{~mm}$ diameter flexible endoscope (STORZ, KARL STORZ GmbH \& Co. KG) was set up and handled with a free-hand technique. Particular attention was paid on avoiding excessive pressure on the spinal cord. Endoscopic navigation, driven upward and downward, showed postinfectious adhesions. The fibrous septa encountered were quite easily dissected, carefully pushing the endoscopy $20 \mathrm{~cm}$ in both directions. The endoscope was pushed till L5 level, to clearly visualize and debride the nervous roots ( - Fig. 1). The anterior and lateral subdural spaces were not explored. Furthermore, we tried to introduce the endoscope through the myelotomy, but the narrow stomy did not allow the insertion. Thanks to the direct visualization of the subarachnoid space it was possible to unleash the arachnoid adherences and get an accurate arachnolysis, both in cranial and caudal spaces. At this point we shaped a silicon-made cannula ( $35 \mathrm{~mm}$ length and $3 \mathrm{~mm}$ outer diameter) in an $\mathrm{S}$ italic form. An s-shaped spindle was inserted into the cannula and then was boiled in sterile water for 1 minute to mold it (-Fig. 2). The top of the cannula was placed through the stomy into the syrinx with the lower part leaning on the posterior face of the spinal cord. Once checked

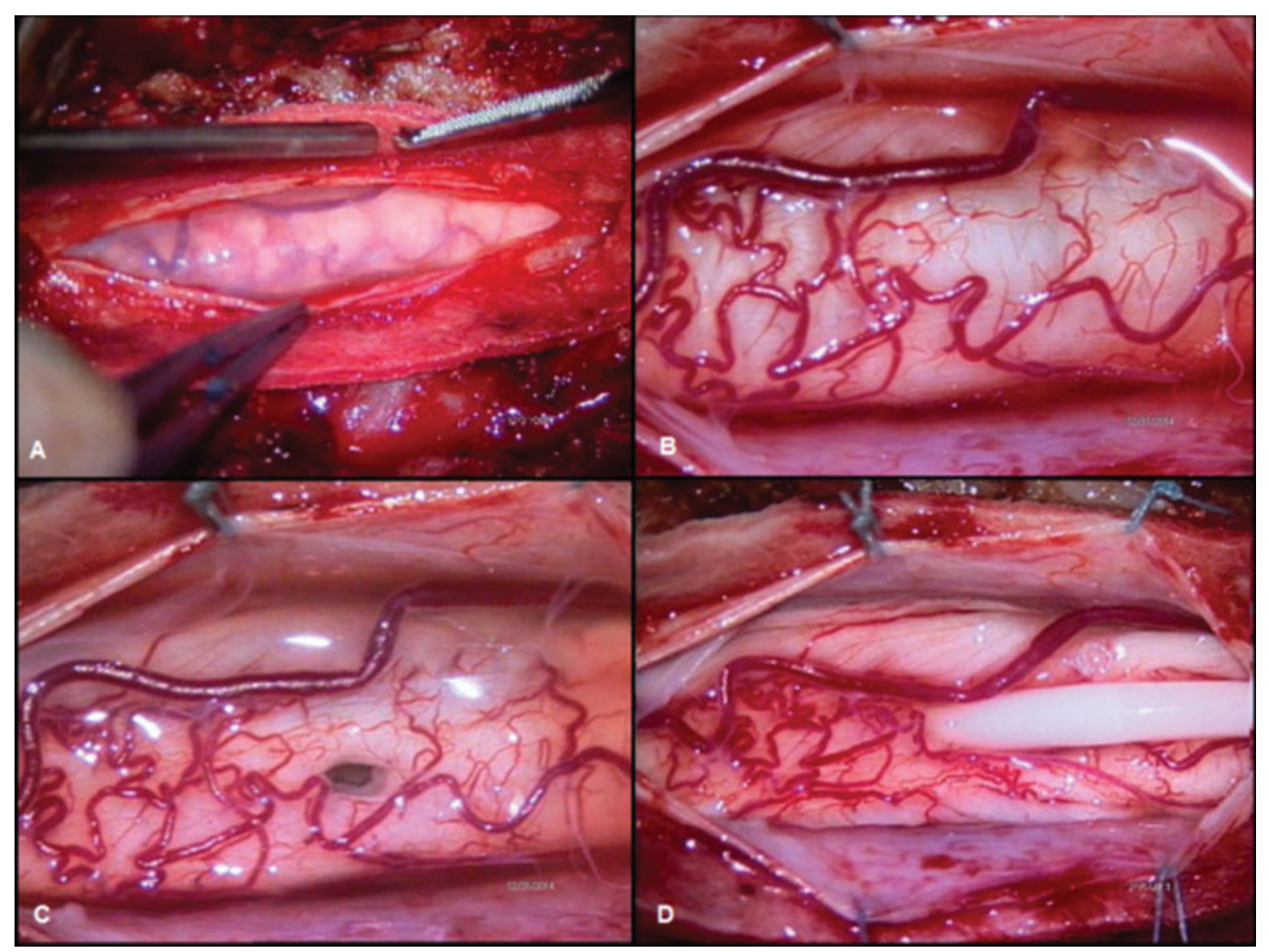

Fig. 3 Intraoperative imaging. (A) Evidence of thickened spinal arachnoid layer. (B) Posterior view of the enlarged spinal cord. (C) A 6-mm myelostomy opened on the posterior midline. (D) The shunt in its definitive position. It is evident the decompression of the spinal cord after the drainage of the syringomyelic cavity. 


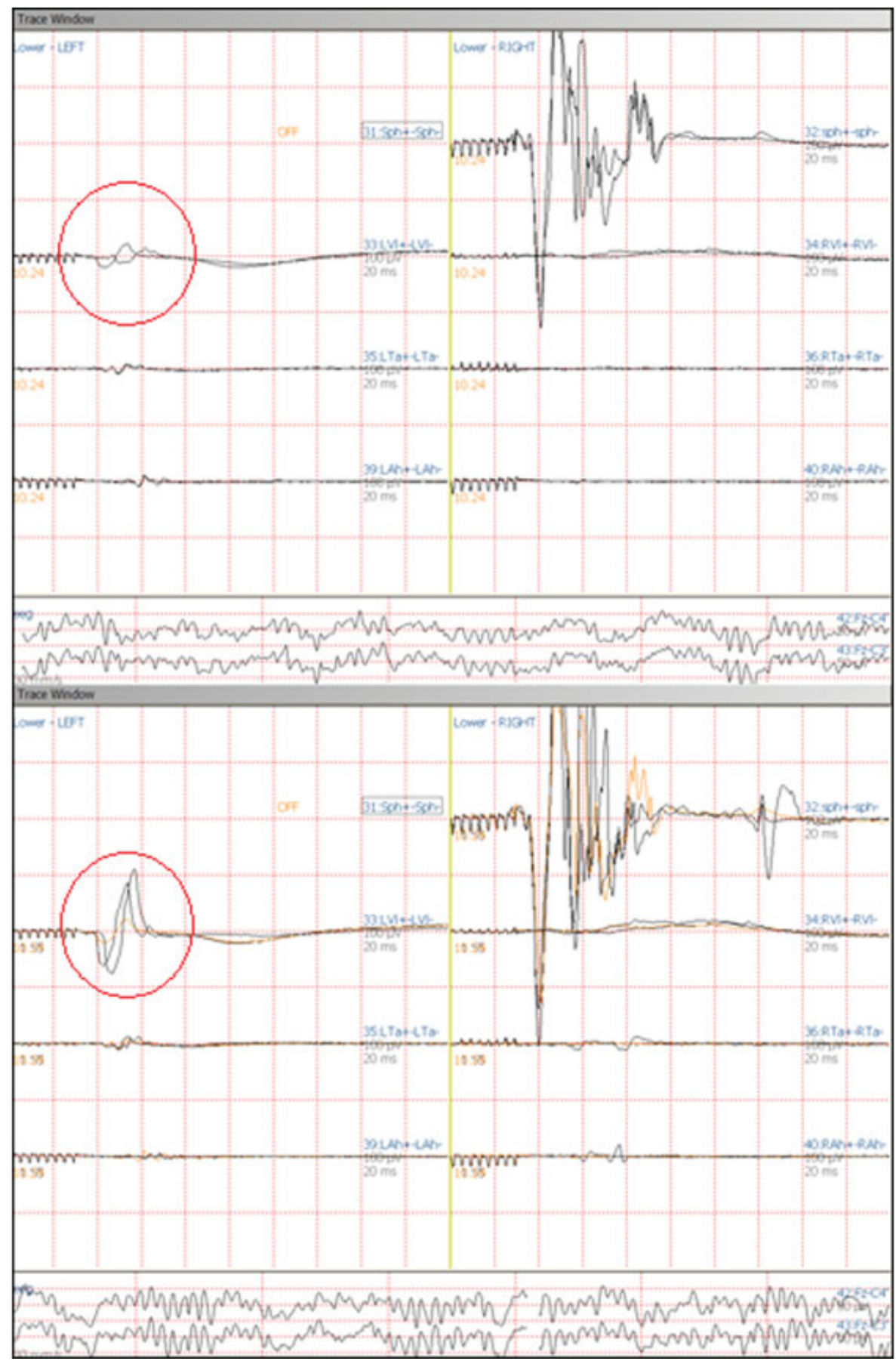

Fig. 4 Motor evoked potentials (MEP) screenshots. Comparison between MEP before the dural opening (up) and MEP after the drainage of the syrinx (down): improvement of the conductivity is particularly evident while monitoring left vastus lateralis.

the proper functioning of the shunt, we fixed it with a drop of fibrin glue (-Fig. 3).

No disturbances in motor evoked potential or hemorrhagic complications occurred during endoscopic navigation. Neurophysiological monitoring showed improvement of the motor evoked potentials after the opening of the dura mater and after the emptying of the syrinx (-Fig. 4). Postoperative follow-up was characterized by a significant improvement of the legs' strength. Early after surgery, the patient was able to walk alone with support and 15 days later he only complaint about a slight weakness in both legs (more evident in the right leg). After 40 days, spine MRI scans showed the reduction of the diameter of the syrinx ( $3 \mathrm{~mm}$ ), the improvement of the CSF flow, and the unchanged position of the subdural shunt (-Fig. 5).

\section{Discussion}

Syringomyelia is a rare condition that affects 8.4 out of 100,000 people in the general population ${ }^{1}$ and is defined 


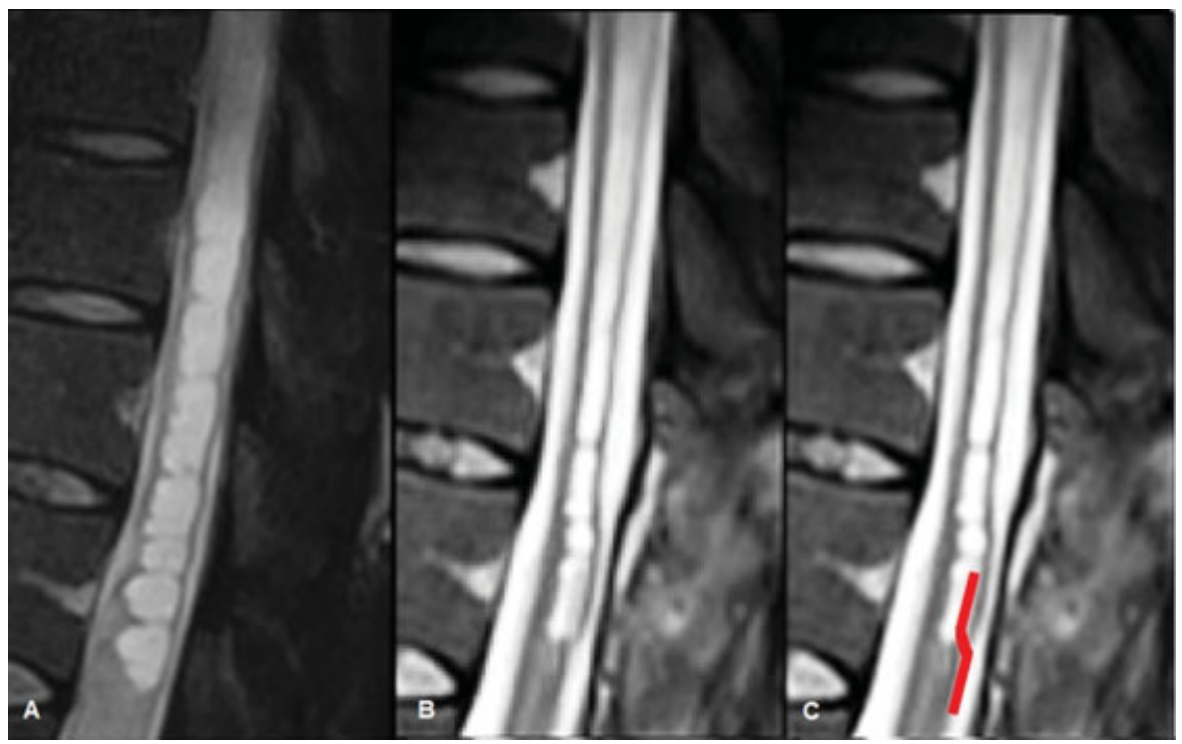

Fig. 5 (A) Midline sagittal T2-weighted preoperative spine MR image of the syrinx. (B) Midline sagittal T2-weighted image from the spine MRI performed 40 days after the operation showing the reduction of the syrinx diameter. The device is barely evident in the lower part of the syrinx. (C) Same image as in B where the position of the silicon shunt has been artificially enhanced. MR, magnetic resonance; MRI, magnetic resonance imaging.

as a cystic formation within the spinal cord. The etiology is still unclear but is often associated with traumatic events, infectious processes, hindbrain herniation-syndromes (Chiari-like) and occasionally craniovertebral junction malformations. ${ }^{11-14}$ In the adult $50 \%$ of cases are associated with Chiari I malformations and the remainder are of acquired nature: whereas $25 \%$ are associated with spinal cord trauma or postinfectious arachnoiditis. ${ }^{15}$ Tuberculosis may affect the vertebrae (Pott disease) and rarely nonosseous structures of the spine. ${ }^{8}$ Posttubercular adhesive arachnoiditis is a rare late complication of tubercular meningitis and its association with syrinx formation ${ }^{15-17}$ is even rarer. Some authors believe that the initial stage of syringomyelia formation in the case of spinal arachnoiditis could be an intramedullary cystic degeneration caused by ischemia as consequence to a circulatory disturbance in the pia-arachnoid layers. The blockage of CSF pathways around the spinal cord contribute to the formation of intramedullary cystic cavities. ${ }^{9}$ Recent studies described how the interstitial edema caused by the pia-arachnoid scarring has a major role in the development of syringomyelia in spinal arachnoiditis. ${ }^{1}$ Disturbances in venous circulation may interfere with CSF absorption and lead to excessive fluid intake from interstitial spaces. This process could expand intramedullary microcystic lesions and eventually form a syrinx. ${ }^{18}$

CSF diversion procedures as syringe-subarachnoidal, syringe-pleural, ${ }^{20}$ and syringe-peritoneal shunt, were widely used in the past, with the evidence of early improvement of symptoms. ${ }^{11,12,21,22}$ Unfortunately long-term effectiveness has been recently questioned because of the high rate of failure or the poor long-term outcome ${ }^{19}$ observed in approximately half of the treated patients. ${ }^{9}$ Aghakhani et al reported a considerable number of recurrences (73\%) and aggravation of symptoms (40\%), after the shunting procedure, for a mean follow-up of 86 months. ${ }^{21}$ Syringe- subarachnoid shunt is the treatment of choice when shunting with the peritoneal space is not feasible, ${ }^{4}$ but also syringe-subpleural shunt have shown a good efficacy for the resolution of the syrinx and it also proved to be useful as rescue procedure in a patient with syringomyelia refractory to the restoration of $\mathrm{CSF}^{23-26}$ A potential issue related to the creation of a channel linking the syrinx to the subarachnoid space could be the developing of flow reversal into the syrinx in particular during Valsalva maneuvers. Furthermore, in tuberculous arachnoiditis, the high protein content of the CSF and the lack of a pressure head between the syrinx and subarachnoid space often lead to blockage of the shunt on a long-term basis. Some authors used a T-tube for syringesubdural shunts. This technique presented some limitations: the development of rotational forces, due to the shunt shape, can damage the spinal cord; the removing of a T-tube, without cord injury, is more difficult in the case of complications such as obstruction, infection, or cord compression (-Table 1). ${ }^{6}$

Several authors proposed arachnolysis to resolve the spinal cord tethering and blockage of the subarachnoid space caused by adhesions. Arachnolysis, without CSF shunting, demonstrated to have excellent results in postadhesive arachnoiditis, regardless of the etiology of the syringomyelia, and a significantly longer symptom-free period before recurrence. ${ }^{27,28}$ In literature, there is no clear consensus about the optimal surgical extent of arachnolysis. Klekamp advocates the use of duraplasty to increase the size of the arachnoid space and to limit tethering, combined with the reduction of bleeding into the arachnoid space. ${ }^{29}$ Nevertheless, in case of treatment failure, CSF diversion could be the last treatment option via any of the aforementioned shunting methods. ${ }^{25}$ However, the surgical outcome following broad arachnoid dissection and syrinx-subarachnoid shunts are limited by the risk of surgical damage to the 


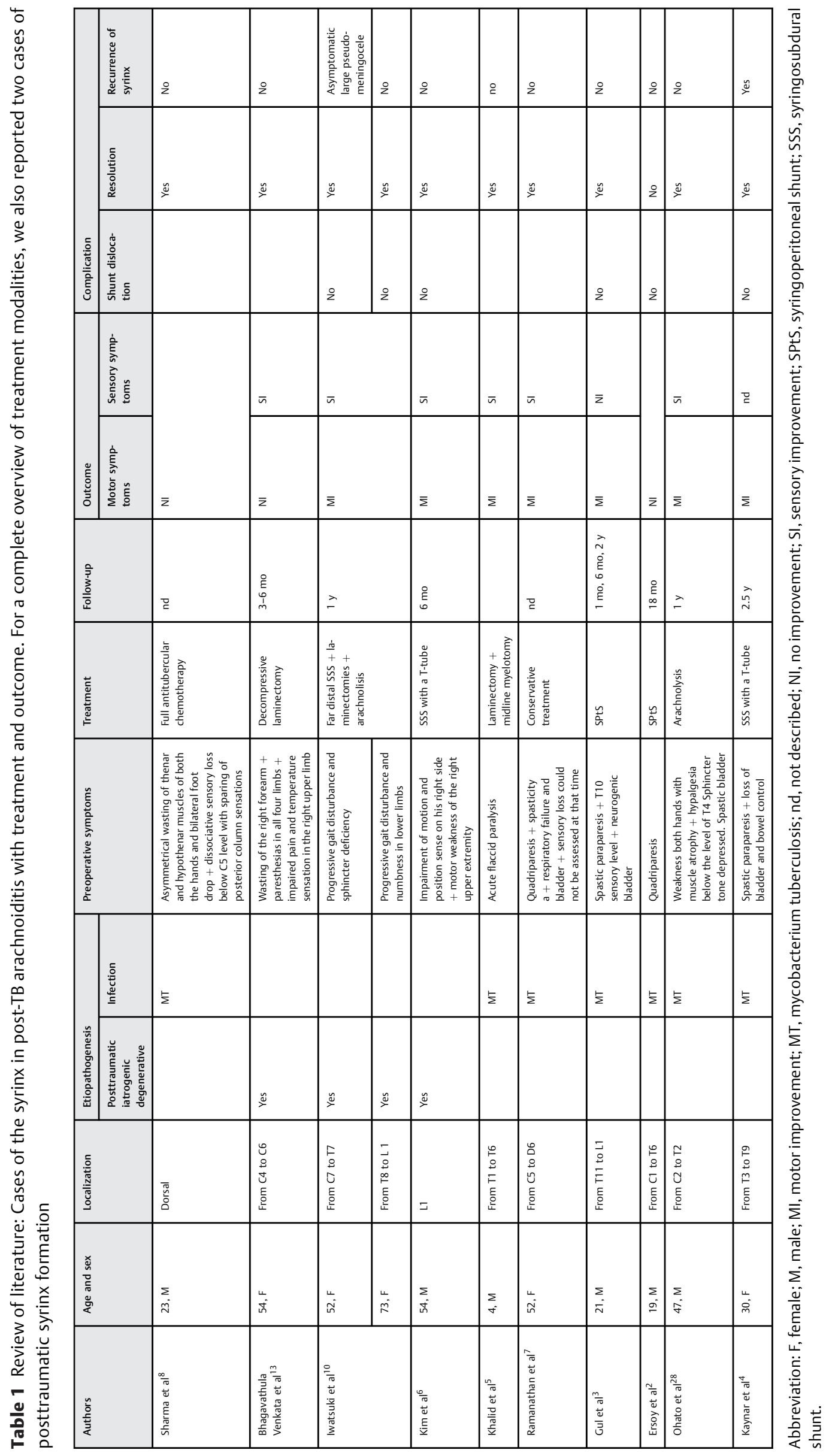




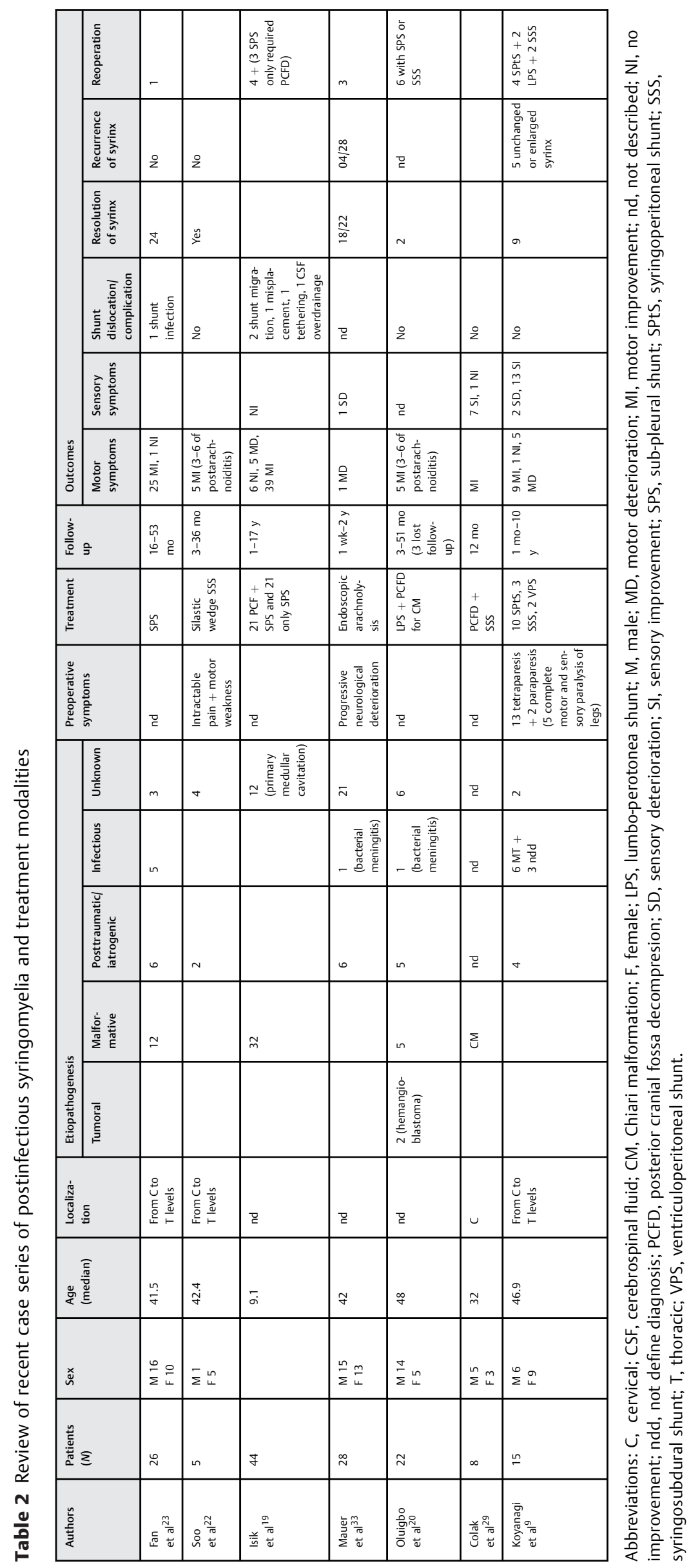


spinal cord and the postoperative formation of new adhesions. ${ }^{30}$ In their multivariate regression analysis, Ghobrial et al showed that CSF diversion did not have a significant impact on the outcome and that arachnolysis was the only surgical treatment to have a significant effect to prevent recurrences and improve the outcome (-Table 2 ). ${ }^{27}$

Endoscopic examination of the spinal cord, cord surface, and syrinx cavities have been reported in the past decades in cadaveric studies, before clinical endoscopic intervention. Endoscopic examination of intradural arachnoid cyst and syrinx have been described as a less invasive procedure than the standard surgical approach ${ }^{31}$ but on the basis of the current understanding of the pathophysiology of syringomyelia it is not considered an effective treatment. ${ }^{16}$ Huewel et al support that the use of a flexible neuroendoscope may have the possibility to perforate the septa which subdivide the cavity under visual control. In their studies, they reported 11 cases of septate syringes, which have been operated using a flexible neuroendoscope. ${ }^{32,33}$ Endoscopes could be safely inserted and approached to the lesions under direct vision, avoiding blood vessels and nerve roots on the spinal cord surface. Also, Endo et al described the use of a flexible endoscope to inspect spinal cord and the subarachnoid space and in some patients, the resection of arachnoid adhesion was attempted. ${ }^{34}$ The use of a flexible endoscope with a diameter bigger than $2.5 \mathrm{~mm}$ presents high risk of injury of the spinal cord or the spinal vessels by the rear parts of the instrument, which cannot be seen by the surgeon. ${ }^{16}$

\section{Conclusion}

In the reported case of posttubercular syringomyelia not responsive to antitubercular therapy and with progressive debilitating deficits we adopted a surgical strategy consisting in syringe-subarachnoid shunting and endoscopic arachnolysis using a flexible endoscope. We observed that shaping the shunt on an S-italic form allowed an easier placement, an increased stability of the implant and an easier revision procedure in case of complications. Furthermore, we support that the endoscope can allow a wider arachnolysis, both cranially and caudally, in comparison to that executed with a microscope. The combination of endoscopic arachnolysis and syringe-subdural shunt proved to have the synergistic effect needed to resolve the syrinx and restore the CSF flow in selected case of posttubercular syringomyelia.

\section{Funding}

No funding was received for this research.

\section{Conflict of Interest}

All authors certify that they have no affiliations with or involvement in any organization or entity with any financial interest (such as honoraria; educational grants; participation in speakers' bureaus; membership, employment, consultancies, stock ownership, or other equity interest; and expert testimony or patent-licensing arrangements), or nonfinancial interest (such as personal or professional relationships, affiliations, knowledge or beliefs) in the subject matter or materials discussed in this article.

\section{Informed Consent}

An informed consent was obtained from all individual participants included in the study.

\section{References}

1 Di Lorenzo N, Cacciola F. Adult syringomielia. Classification, pathogenesis and therapeutic approaches. J Neurosurg Sci 2005;49(03):65-72

2 Ersoy Y, Ates O, Onal C, et al. Cerebellar abscess and syringomyelia due to isoniazid-resistant Mycobacterium tuberculosis. J Clin Neurosci 2007;14(01):86-89

3 Gul S, Celebı G, Kalayci M, Acikgoz B. Syringomyelia and intradural extramedullary tuberculoma of the spinal cord as a late complication of tuberculous meningitis. Turk Neurosurg 2010;20(04): 561-565

4 Kaynar MY, Koçer N, Gençosmanoğlu BE, Hanci M. Syringomyeliaas a late complication of tuberculous meningitis. Acta Neurochir (Wien) 2000;142(08):935-938, discussion 938-939

5 Khalid M, Khalid S, Mittal S, Ahmad U. Intramedullary tubercular abscess with syrinx formation. J Pediatr Neurosci 2012;7(01): 61-63

6 Kim SH, Choi SW, Youm JY, Kwon HJ. Syringo-subarachnoidperitoneal shunt using T-tube for treatment of post-traumatic syringomyelia. J Korean Neurosurg Soc 2012;52(01):58-61

7 Ramanathan SR, Ahluwalia T. Rare complication: Acute syringomyelia due to tuberculoma and tubercular meningitis. J Neurosci Rural Pract 2010;1(02):123-125

8 Sharma B, Nagpal K, Handa R, Gupta P. Intradural extramedullary and intracranial tuberculomas with concurrent communicating syringomyelia. BMJ Case Rep 2014;2014(14):bcr2013201368

9 Koyanagi I, Iwasaki Y, Hida K, Houkin K. Clinical features and pathomechanisms of syringomyelia associated with spinal arachnoiditis. Surg Neurol 2005;63(04):350-355, discussion 355-356

10 Iwatsuki K, Yoshimine T, Ohnishi Y, Ninomiya K, Moriwaki T, Ohkawa T. Syringomyelia associated with spinal arachnoiditis treated by partial arachnoid dissection and syrinx-far distal subarachnoid shunt. Clin Med Insights Case Rep 2014;7:107-110

11 Barbaro NM, Wilson CB, Gutin PH, Edwards MS. Surgical treatment of syringomyelia. Favorable results with syringoperitoneal shunting. J Neurosurg 1984;61(03):531-538

12 Ram Z, Findler G, Tadmor R, Sahar A, Shacked I. Syringopleural shunt for the treatment of syringomyelia. Technical note. Spine 1990;15(03):231-233

13 Bhagavathula Venkata SS, Arimappamagan A, Lafazanos S, Pruthi N. Syringomyelia secondary to cervical spondylosis: Case report and review of literature. J Neurosci Rural Pract 2014;5(Suppl 1): S78-S82

14 Brodbelt AR, Stoodley MA. Post-traumatic syringomyelia: a review. J Clin Neurosci 2003;10(04):401-408

15 Makkar G, Srivastava A, Aggarwal AK. Intradural extramedullary spinal tuberculoma-an uncommon entity. Indian J Radiol Imaging 2003;13:103-104

16 Maxmauer U, Danz B, Gottschalk A, Kunz U. Endoscope-assisted surgery of spinal intradural adhesions in the presence of cerebrospinal fluid flow obstruction. Spine 2011;36(12):E773-E779

17 Muthukumar N, Sureshkumar V. Concurrent syringomyelia and intradural extramedullary tuberculoma as late complications of tuberculous meningitis. J Clin Neurosci 2007;14(12): 1225-1230 
18 Josephson A, Greitz D, Klason T, Olson L, Spenger C. A spinal thecal sac constriction model supports the theory that induced pressure gradients in the cord cause edema and cyst formation. Neurosurgery 2001;48(03):636-645, discussion 645-646

19 Isik N, Elmaci I, Isik N, et al. Long-term results and complications of the syringopleural shunting for treatment of syringomyelia: a clinical study. Br J Neurosurg 2013;27(01):91-99

20 Oluigbo CO, Thacker K, Flint G. The role of lumboperitoneal shunts in the treatment of syringomyelia. J Neurosurg Spine 2010;13(01):133-138

21 Aghakhani N, Baussart B, David P, et al. Surgical treatment of posttraumatic syringomyelia. Neurosurgery 2010;66(06):1120-1127, discussion 1127

22 Soo TM, Sandquist L, Tong D, Barrett R. Surgical treatment of idiopathic syringomyelia: Silastic wedge syringosubarachnoid shunting technique. Surg Neurol Int 2014;5:114

23 Fan T, Zhao X, Zhao H, et al. Treatment of selected syringomyelias with syringo-pleural shunt: the experience with a consecutive 26 cases. Clin Neurol Neurosurg 2015;137:50-56

24 Colak A, Boran BO, Kutlay M, Demirican N. A modified technique for syringo-subarachnoid shunt for treatment of syringomyelia. J Clin Neurosci 2005;12(06):677-679

25 Cacciola F, Capozza M, Perrini P, Benedetto N, Di Lorenzo N. Syringopleural shunt as a rescue procedure in patients with syringomyelia refractory to restoration of cerebrospinal fluid flow. Neurosurgery 2009;65(03):471-476, discussion 476
26 Lund-Johansen M, Wester K. Syringomyelia treated with a nonvalved syringoperitoneal shunt: a follow-up study. Neurosurgery 1997;41(04):858-864, discussion 864-865

27 Ghobrial GM, Dalyai RT, Maltenfort MG, Prasad SK, Harrop JS, Sharan AD. Arachnolysis or cerebrospinal fluid diversion for adult-onset syringomyelia? A Systematic review of the literature. World Neurosurg 2015;83(05):829-835

28 Ohata K, Gotoh T, Matsusaka Y, et al. Surgical management of syringomyelia associated with spinal adhesive arachnoiditis. J Clin Neurosci 2001;8(01):40-42

29 Klekamp J. Treatment of posttraumatic syringomyelia. J Neurosurg Spine 2012;17(03):199-211

30 Caplan LR, Norohna AB, Amico LL. Syringomyelia and arachnoiditis. J Neurol Neurosurg Psychiatry 1990;53(02):106-113

31 Eguchi T, Tamaki N, Kurata H. Endoscopy of the spinal cord: cadaveric study and clinical experience. Minim Invasive Neurosurg 1999;42(03):146-151

32 Huewel N, Perneczky A, Urban V, Fries G. Neuroendoscopic technique for the operative treatment of septated syringomyelia. Acta Neurochir Suppl (Wien) 1992;54:59-62

33 Mauer UM, Gottschalk A, Kunz U, Schulz C. Arachnoscopy: a special application of spinal intradural endoscopy. Neurosurg Focus 2011;30(04):E7

34 Endo T, Takahashi T, Jokura H, Tominaga T. Surgical treatment of spinal intradural arachnoid cysts using endoscopy. J Neurosurg Spine 2010;12(06):641-646 